\title{
Chemometric characterization of three varietal olive oils (Cvs. Cobrançosa, Madural and Verdeal Transmontana) extracted from olives with different maturation indices
}

\author{
Luís C. Matos ${ }^{\mathrm{a}, \mathrm{b}}$, Sara C. Cunha ${ }^{\mathrm{a}, \mathrm{d}}$, Joana S. Amaral ${ }^{\mathrm{a}, \mathrm{b}}$, José A. Pereira ${ }^{\mathrm{c}}$, \\ Paula B. Andrade ${ }^{\text {b }}$, Rosa M. Seabra ${ }^{\text {b }}$, Beatriz P.P. Oliveira ${ }^{\mathrm{a}, *}$ \\ ${ }^{a}$ REQUIMTE, Serviço de Bromatologia, Faculdade de Farmácia, Universidade do Porto, Rua Aníbal Cunha, 164, 4099-030 Porto, Portugal \\ ${ }^{\mathrm{b}}$ Serviço de Farmacognosia, Faculdade de Farmácia, Universidade do Porto, R. Aníbal Cunha, 164, 4099-030 Porto, Portugal \\ ${ }^{\mathrm{c}}$ Escola Superior Agrária, Instituto Politécnico de Bragança, Quinta de Sta. Apolónia, Apartado 134, 5301-857 Bragança, Portugal \\ d I.S.E.I.T-M. Av. 25 de Abril, 5370 Mirandela, Portugal
}

Received 11 July 2005; received in revised form 8 November 2005; accepted 29 December 2005

\begin{abstract}
This paper evaluates the usefulness of three chemical parameters (compositions on tocopherols, sterols and fatty acids) as a tool to discriminate three varietal olive oils (Cvs. Cobrançosa, Madural and Verdeal Transmontana), which are permitted cultivars for the production of "Trás-os-Montes olive oil", a Portuguese protected designation of origin (PDO) product. The olives were collected during the year crop 2000/2001 from the same orchard, in order to eliminate the geographical and climatic influences. Lots with different maturation indices were prepared to allow the evaluation of the ripening stage on the characteristics of varietal olive oils produced from each cultivar. Statistical methods such as multivariate analysis of variance (MANOVA), principal components analysis (PCA) and cluster analysis were used to evaluate significant differences on the studied parameters. Regarding the results, the three cultivars were clearly discriminated.
\end{abstract}

(C) 2006 Elsevier Ltd. All rights reserved.

Keywords: Portuguese virgin olive oil; Ripening; Chemometrics; PDO

\section{Introduction}

Olive oil is obtained from the fruit of olive trees (Olea europaea L.) and is a genuine fruit juice with excellent nutritional, sensorial and functional quality. It represents a typical lipid source of the Mediterranean diet, which consumption has been associated with a low incidence of cardiovascular diseases, neurological disorders, breast and colon cancers, as well as with hipolipidemic and antioxidant properties (Gimeno et al., 2002; Medeiros, 2001). These benefits have been related either to its well-balanced fatty acid composition, where oleic acid is the main compo-

\footnotetext{
* Corresponding author. Tel.: +35122207 8927; fax: +351222003977.

E-mail address: beatoliv@ff.up.pt (B.P.P. Oliveira).
}

nent, or to the presence of minor biomolecules, such as vitamins and natural antioxidants (Medeiros, 2001). These characteristics, as a whole, make olive oil a premium food and, therefore, a product of major economical importance in the Mediterranean area.

Olive oil quality is influenced by a great number of factors among which the cultivar and the olive ripening stage are two of the most important ones (Garcia, Seller, \& Pérez-Camino, 1996; Kiritsakis, 1998; Rotondi et al., 2004; Zamora, Alaiz, \& Hidalgo, 2001). Along the ripening, several metabolic processes take place in olives with subsequent variations on profiles of some compounds. These changes are reflected on the quality grade, sensorial characteristics, oxidative stability and/or nutritional value of the obtained product. Polyphenols, tocopherols, chlorophyllic pigments and carotenoids are examples of 
compounds involved in this phenomenon as well as the fatty acid and sterol compositions.

There are different cultivars of $O$. europaea, each one with specific physical and biochemical characteristics, providing olive oils with typical compositions and performances. The aim of this work was to evaluate, compare and characterize the performances of varietal olive oils obtained from Cvs. Cobrançosa, Madural and Verdeal Transmontana based on some of its most important components. These three cultivars account for more than $90 \%$ of olive cultivation area in Trás-Os-Montes (Portugal) and, together with cv. Cordovil, are the only permitted cultivars in the "Trás-Os-Montes olive oil" (protected designation of origin, PDO). The trees used in this study belong to the same orchard and, consequently, are subjected to the same climate conditions and agricultural practices. The olives were collected during the year crop 2000/ 2001. Lots with different maturation indices were prepared to allow the evaluation of the ripening stage effect on the characteristics of olive oils produced from each cultivar. In this way, we can be sure that the only factors affecting the differences among samples are the cultivar and the ripening stage, the only influences that are aimed to study. A total of 18 samples were analyzed: 7 from $\mathrm{Cv}$. Cobrançosa (maturation indices 1-7), 5 from Cv. Madural (maturation indices 3-7) and 6 from Cv. Verdeal Transmontana (maturation indices 1-6). In all samples the chemical parameters evaluated were the compositions on tocopherols, sterols and fatty acids. The results were subjected to statistical analysis in order to evaluate the influence of cultivar and ripening stage on those parameters and to check if PCA of the evaluated parameters could be a tool for cultivar and ripening stage discrimination.

\section{Materials and methods}

\subsection{Sampling}

The studied cultivars were Cvs. Cobrançosa, Madural and Verdeal Transmontana. The trees were identified and carefully marked, and five trees of each cultivar have been sampled. The olive fruits were handpicked in "Mascarenhas-Paradela", an orchard $10 \mathrm{~km}$ North from Mirandela, in the Northeast of Portugal (U.T.M. 29 PG5602). The orchard has 6 ha with a planting density of $9 \times 9 \mathrm{~m}$; trees have more than 40 years; the prune is made each three years; it is not irrigated and the soil is mobilized 2-3 times each year. This olive grove is kept under Biological Agricultural system and did not have any crop health control treatment in the last 10 years. $\mathrm{Cv}$. Cobrançosa is the more representative cultivar $(80 \%$ of the trees). The olives were harvested in the crop year $2000 / 2001$ in three different days $(30 / 10,22 / 11$ and 5/ 12), in the four orientations of the trees, at the operator height. From each tree, only healthy fruits were picked. After harvest, olive fruits were immediately transported to the laboratory, carefully blended and, in a hundred olives randomly taken from each cultivar and harvest date, the maturation indices (MI) were determined. This parameter is function of fruit colour in both skin and pulp and was determined according to the proposals of the Estación de Olivicultura y Elaiotecnia, Jaén, Spain (Hermoso et al., 1991). Following this procedure 18 samples were obtained: seven samples for $\mathrm{Cv}$. Cobrançosa (MI 1-7), five for Cv. Madural (MI 3-7) and six for Cv. Verdeal Transmontana (MI 1-6). From each group, a $1 \mathrm{~kg}$ of olives were randomly taken and submitted to oil extraction.

\subsection{Oil extraction}

An Abencor analyzer (Comercial Abengoa S.A., Sevilla, Spain) was used to process the olives in a pilot extraction plant. The unit consists of three essential elements: the mill, the thermo beater, and the pulp centrifuge. After being processed in the mill, the oil was separated by decanting, transferred into dark glass bottles, and stored in the dark at $4{ }^{\circ} \mathrm{C}$. Before the analytical procedures the samples were dehydrated with anhydrous sodium sulfate and subsequently filtered through filter paper.

\subsection{Standards}

A mixture of 37 FAMEs (standard 47885-U) and the individual fatty acid isomers cis-9-trans-12-octadecadienoate (C18:2ct), trans-9-cis-12-octadecadienoate (C18:2tc) were obtained from Supelco (Bellefonte, PA, USA). Cholestanol, cholesterol, campesterol, stigmasterol, $\beta$-sitosterol, $\beta$-sitostanol and betulin were purchased from Sigma (St. Louis, USA). $\alpha-, \beta-, \gamma$ - and $\delta$-tocopherols were obtained from Calbiochem (La Jolla, CA, USA).

\subsection{Tocopherol composition}

Tocopherol composition was evaluated following the method described in Gama, Casal, Oliveira, and Ferreira (2000). A $0.1 \mathrm{~g}$ of olive oil was blended with $10 \mathrm{ml}$ of $n$-hexane and homogenized by stirring. Sample preparation was conducted in dark and tubes containing the samples were always wrapped in aluminium foil. The mixture was filtered by membrane (Schleicher and Shuell $0.2 \mu \mathrm{m} ; \varnothing 13 \mathrm{~mm}$, pure polyamide) and analyzed by HPLC. The chromatographic separation of the compounds was achieved with a normal-phase LiChrosorb SI $60(5 \mu \mathrm{m} ; 25 \times 0.4 \mathrm{~cm})$ column from Merck (Darmstadt, Germany). The effluent used was a mixture of $n$-hexane and 2-propanol (99.7:0.3). Elution was performed at a solvent flow rate of $1.7 \mathrm{ml} / \mathrm{min}$. The effluent was monitored with diode array and fluorimetric (290 and $330 \mathrm{~nm}$ as excitation and emission wavelengths respectively) detectors connected in series. Data were analyzed in the Borwin PDA Controller Software (JMBS, France). Tocopherols ( $\alpha, \beta$ and $\gamma$ ) were identified by chromatographic comparisons with authentic standards, by coelution and by their UV spectra. 


\subsection{Sterol composition}

Sterol composition was evaluated by GLC/FID/capillary column following the NP EN ISO 12228. Briefly, after addition of $1.0 \mathrm{ml}$ of internal standard solution (betulin $1.0 \mathrm{mg} / \mathrm{ml}$ ) ca. $250 \mathrm{mg}$ of oil sample was saponified with an ethanolic potassium hydroxide solution; the unsaponifiable fraction was isolated by solid phase extraction on an aluminum oxide column and the steroid fraction was obtained after TLC with $n$-hexane/diethyl ether 1:1 (v/v) as developing solvent and a methanol spray to visualize the band. The trimethylsilylethers were obtained by the addition of 1-methylimidazole and $N$-methyl- $N$-(trimethylsilyl)-hepta-fluorobutyramide (MSHFBA). The sterol profile was analyzed on the same equipment used for fatty acid analysis, with a $30 \mathrm{~m} \times 0.25 \mathrm{~mm}$ i.d., $0.25 \mu \mathrm{m}$ DB-5MS column (J\&W Scientific, Folsom, CA, USA) with a maximum operating temperature of $325^{\circ} \mathrm{C}$. The temperature of the injector and the detector were both $320^{\circ} \mathrm{C}$. The column temperature was $250^{\circ} \mathrm{C}$ and programmed to increase at a rate of $2{ }^{\circ} \mathrm{C} / \mathrm{min}$ to $300^{\circ} \mathrm{C}$ and then held for $12 \mathrm{~min}$. The carrier gas used was helium at an internal pressure of $100 \mathrm{kPa}$. The split ratio was 1:50 and the injected volume was $1.5 \mu 1$. The total sterol content was determined considering all peaks of sterols eluted between cholesterol and $\Delta^{7}$ avenasterol. Identification was achieved by comparing the relative retention times from samples with those obtained with standards. Clerosterol, $\Delta^{5}$-avenasterol and $\Delta^{7}$-avenasterol were tentatively identified by comparison with references (Firestone \& Reina, 1996; Kamm, Dionisi, Hischenhuber, \& Engel, 2001) and with samples of olive and sunflower oils. $\beta$-Sitostanol and $\Delta^{5}$-avenasterol eluted very close and therefore they were quantified as $\Delta^{5}$ avenasterol.

\subsection{Fatty acid composition}

Fatty acids were determined by GLC/FID/capillary column using the same methodology described in Oliveira and Ferreira (1996).

Fatty acids were measured as their methyl esters after hydrolysis with an $11 \mathrm{~g} / 1$ methanolic potassium hydroxide solution, methyl esterification with $\mathrm{BF}_{3} / \mathrm{MeOH}$ and extraction with $n$-heptane. The analysis was carried out on a Chrompack CP 9001 chromatograph (Chrompack, Middelburg, The Netherlands) equipped with a split-splitless injector, a FID and a Chrompack CP-9050 auto sampler. The temperatures of the injector and detector were 230 and $270{ }^{\circ} \mathrm{C}$ respectively. Separation was achieved on a $50 \mathrm{~m} \times 0.25 \mathrm{~mm}$ i.d. fused silica capillary column coated with a $0.19 \mu \mathrm{m}$ film of CP-Sil 88 (Chrompack, Middelburg, The Netherlands). The column temperature was $160^{\circ} \mathrm{C}$, $1 \mathrm{~min}$ hold, and then programmed to increase to $239^{\circ} \mathrm{C}$ at a rate of $4{ }^{\circ} \mathrm{C} / \mathrm{min}$ and then $10 \mathrm{~min}$ hold. Helium was used as carrier gas at an internal pressure of $120 \mathrm{kPa}$. The split ratio was 1:50 and the injected volume was $1.2 \mu 1$. The results are expressed in relative percentage of each fatty acid, calculated by internal normalization of the chromatographic peak area. Fatty acids were identified by comparing the relative retention times of FAME peaks from samples with those from standards.

\subsection{Statistical analysis}

Results were submitted to multivariate analysis of variance (MANOVA) with the purpose of testing the significant differences between mean values of the evaluated parameters by comparing variances. In other words we compared the variance due to the between-groups with the within-group variability. These latter were tested for statistical significance and, if significant, we rejected the null hypothesis of no differences between means, and accepted the alternative hypothesis that the means were different from each other. One-way MANOVA was used because our design had one single categorical independent variable (cultivar type) and multiple dependent variables (chemical parameters). Multivariate test of significance was performed and Wilk's lambda was observed. Alternative $t$-test for independent samples was used with the purpose of comparing differences in means between two types of cultivars. All the combinations of cultivars pairs were tested. Principal components analysis (PCA) was performed to detect structure in the relationships between variables, allowing its classification and the separation of each cultivar. Variables used in PCA were selected regarding to the MANOVA and $t$-test results. This procedure allowed the minimization of variables, and those that were selected became the principal explanation to the variability between cultivars, improving the separation and making easier the understanding of what were the stronger factors that were the base of distinction. Eigenvalues were also observed and, for each analysis, two factors were enough to explain almost all the variability. Cluster analysis was also performed in order to attempt the grouping of samples according to the similarities observed in some chemical parameters. The vertical hierarchical tree plot was performed considering the Euclidian distances of data projected in a multidimensional space. Besides, the clusters linkage was made by the Ward's method. Results are shown as figures and tables. One-way MANOVA, $t$-test for independent groups, PCA and cluster analysis were performed with Statistica for Windows release 6.0.

\section{Results and discussion}

Vitamin $\mathrm{E}$ is a term used to refer a group of minor but ubiquitous lipid-soluble compounds, comprising four tocopherols $(\alpha-, \beta-, \gamma-$ and $\delta$-T) and four tocotrienols $(\alpha-, \beta-$, $\gamma$ - and $\delta$-TTR). These compounds are believed to be involved in a diversity of physiological and biochemical functions, mainly due to its action as antioxidant, but also by its action as a membrane stabilizer (Azzi \& Stocker, 2000). In olive oil the compounds usually described are those which were also detected in this work, that is: 
$\alpha, \beta$ - and $\gamma$-tocopherols (Aguilera et al., 2005; Beltrán, Aguilera, Del Rio, Sanchez, \& Martinez, 2005). Together with phenolic compounds they are responsible by the oxidative stability of olive oil and, therefore, for its shelf life with special emphasis for $\alpha$-tocopherol (Mateos, Dominguez, Espartero, \& Cert, 2003).

Table 1 reports the tocopherol composition of the studied samples. In all samples, and as expected for olive oils (Aguilera et al., 2005; Beltrán et al., 2005) $\alpha$-tocopherol is by far the most abundant isoform of vitamin E. In any of the cultivars, the content of $\alpha$-tocopherol decreases along the ripening. The content of $\beta$-tocopherol showed a good stability while that of $\gamma$ isoform exhibited a slight increase. This behaviour has already been found for other cultivars (Aguilera et al., 2005; Beltrán et al., 2005; Gutiérrez, Jímenez, Ruíz, \& Albi, 1999). The three cultivars under study can be clearly distinguished by the total amounts of tocopherols $(189-139 \mathrm{mg} / \mathrm{kg}$ in $\mathrm{Cv}$. Verdeal Transmontana, $226-209 \mathrm{mg} / \mathrm{kg}$ in Cv. Madural and $298-238 \mathrm{mg} / \mathrm{kg}$ in $\mathrm{Cv}$. Cobrançosa) but also by the individual contents of $\alpha$ - and $\gamma$-tocopherols.

Tocopherol composition of the three cultivars showed highly significant differences $(p<0.01)$ and Wilk's lambda was 0.018 . The three homologous were used in PCA analysis and two factors were selected justifying $96.05 \%$ of total variance (Factor 1: 75.94\%; Factor 2: 20.11\%). Regarding these factors, the three cultivars could be discriminated on the factor-plane (Fig. 1).

Table 1

Tocopherols composition $(\mathrm{mg} / \mathrm{kg})^{\mathrm{a}}$ of Cvs. Cobrançosa, Madural and Verdeal Transmontana virgin olive oils extracted from olives with different maturation indices

\begin{tabular}{|c|c|c|c|c|}
\hline & \multicolumn{4}{|c|}{ Tocopherol contents $(\mathrm{mg} / \mathrm{kg})$} \\
\hline & $\alpha$ & $\beta$ & $\gamma$ & Tota \\
\hline \multicolumn{5}{|c|}{ Cv. Cobrançosa } \\
\hline MI 1 & $291.7 \pm 2.4$ & $0.9 \pm 0.1$ & $5.4 \pm 0.1$ & 298.0 \\
\hline MI 2 & $252.9 \pm 0.9$ & $0.9 \pm 0.0$ & $8.0 \pm 0.1$ & 261.8 \\
\hline MI 3 & $246.6 \pm 1.6$ & $1.0 \pm 0.1$ & $13.0 \pm 0.0$ & 260.6 \\
\hline MI 4 & $222.6 \pm 1.2$ & $0.9 \pm 0.0$ & $12.0 \pm 0.0$ & 235.5 \\
\hline MI 5 & $224.8 \pm 3.6$ & $1.0 \pm 0.0$ & $16.1 \pm 0.1$ & 241.9 \\
\hline MI 6 & $234.8 \pm 0.3$ & $1.0 \pm 0.1$ & $15.9 \pm 0.1$ & 251.6 \\
\hline MI 7 & $221.4 \pm 1.7$ & $1.0 \pm 0.1$ & $15.7 \pm 0.0$ & 238.1 \\
\hline \multicolumn{5}{|c|}{ Cv. Madural } \\
\hline MI 3 & $219.9 \pm 0.8$ & $0.9 \pm 0.1$ & $5.1 \pm 0.1$ & 225.8 \\
\hline MI 4 & $212.1 \pm 1.5$ & $0.9 \pm 0.1$ & $7.6 \pm 0.0$ & 220. \\
\hline MI 5 & $218.8 \pm 2.1$ & $0.9 \pm 0.0$ & $7.1 \pm 0.1$ & 226.8 \\
\hline MI 6 & $209.1 \pm 0.4$ & $0.9 \pm 0.1$ & $6.3 \pm 0.1$ & 216.3 \\
\hline MI 7 & $202.2 \pm 0.6$ & $0.8 \pm 0.1$ & $5.8 \pm 0.0$ & 208.8 \\
\hline \multicolumn{5}{|c|}{ Cv. Verdeal Transmontana } \\
\hline MI 1 & $188.5 \pm 2.2$ & $0.9 \pm 0.1$ & $0.0 \pm 0.1$ & 189. \\
\hline MI 2 & $169.4 \pm 2.8$ & $0.9 \pm 0.1$ & $1.1 \pm 0.0$ & 171.3 \\
\hline MI 3 & $135.4 \pm 0.3$ & $0.9 \pm 0.1$ & $3.1 \pm 0.1$ & 139. \\
\hline MI 4 & $145.5 \pm 0.8$ & $0.9 \pm 0.0$ & $2.9 \pm 0.1$ & 149.3 \\
\hline MI 5 & $146.1 \pm 1.1$ & $0.9 \pm 0.1$ & $3.7 \pm 0.1$ & 150.6 \\
\hline MI 6 & $133.6 \pm 1.4$ & $0.9 \pm 0.1$ & $4.0 \pm 0.1$ & 138.5 \\
\hline
\end{tabular}

\footnotetext{
${ }^{\mathrm{a}}$ Mean and standard deviation for a confidence coefficient of $95 \%$.
}

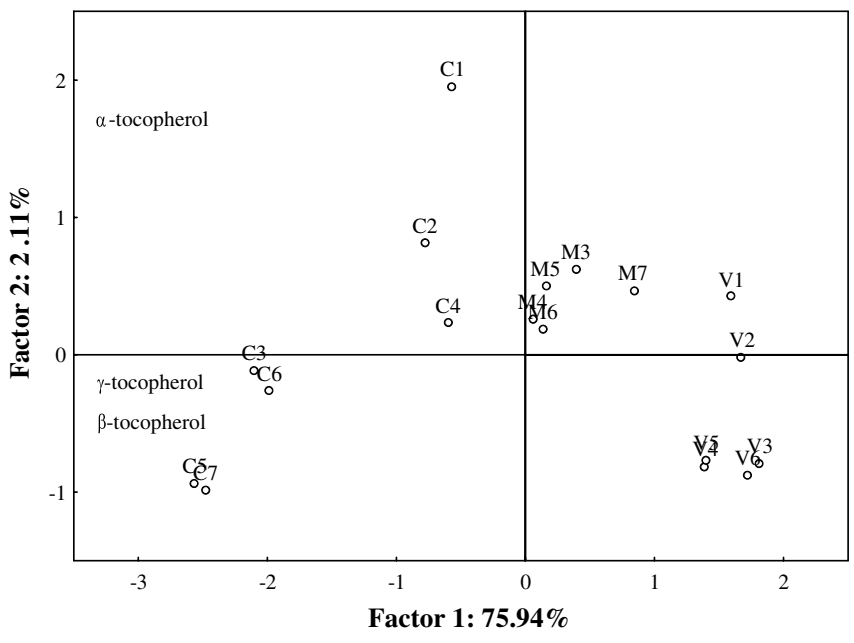

Fig. 1. Principal components analysis based on tocopherol profiles of Cvs. Cobrançosa, Madural and Verdeal Transmontana virgin olive oils extracted from olives with different maturation indices.

Sterols are major constituents of the unsaponifiable fraction and their content corresponds to around $20 \%$ of the unsaponifiable matter of olive oil. Research has shown that each oily fruit has a characteristic sterol profile which makes it determination an important tool for checking the genuineness of an oil (Gutiérrez, Varona, \& Albi, 2000; Salvador, Aranda, \& Fregapane, 1998). They are important components for the stability of the oil since at high temperature they act as inhibitors of polymerization reactions (Velasco \& Dobarganes, 2002). In the present work, seven sterols were detected and quantified and the results obtained are displayed in Table 2. Generally, a decreasing tendency is observed along the ripeness in the values of total sterols, as already observed for Cvs. Cornicabra, Picual and Hojiblanca (Gutiérrez et al., 1999; Salvador, Aranda, \& Fregapane, 2001). Contrarily to the described for these same cultivars, the values for $\Delta^{5}$-avenasterol did not show a clear tendency in any of the cultivars subjected to the present study.

All of the analyzed samples exhibited total sterol far above the $1000 \mathrm{mg} / \mathrm{kg}$ demanded by the EU legislation and all of them contain more the demanded threshold value of $93 \%$ of apparent $\beta$-sitosterol (which in this case is the sum of $\beta$-sitosterol, clerosterol and $\Delta^{5}$-avenasterol).

MANOVA results showed that cultivars presented significant differences regarding stigmasterol and $\Delta^{7}$-avenastenol contents $(p<0.05)$ and highly significant regarding $\Delta^{5}$ avenasterol $(p<0.01)$. Despite these results, the sterols chosen to PCA analysis were also selected by their abundance in the oils. These sterols stigmasterol, clerosterol, $\beta$-sitosterol and $\Delta^{5}$-avenasterol. Two factors were selected justifying $89.27 \%$ of total variance (Factor 1: $73.48 \%$; Factor 2: $15.78 \%$ ). The values were plotted and the cultivars discriminated (Fig. 2) although the separation was less evident than that observed when PCA was performed with the other chemical parameters. 
Table 2

Sterol composition $(\mathrm{mg} / 100 \mathrm{mg})^{\mathrm{a}}$ of Cvs. Cobrançosa, Madural and Verdeal Transmontana virgin olive oils extracted from olives with different maturation indices

\begin{tabular}{|c|c|c|c|c|c|c|c|c|}
\hline & \multicolumn{8}{|c|}{ Sterol parameter } \\
\hline & Cholesterol & Campesterol & Stigmasterol & Clerosterol & $\beta$-Sitosterol & $\Delta^{5}$-Avenasterol & $\Delta^{7}$-Avenasterol & Total \\
\hline \multicolumn{9}{|c|}{ Cv. Cobrançosa } \\
\hline MI 2 & $0.29 \pm 0.04$ & $5.36 \pm 0.04$ & $1.08 \pm 0.04$ & $1.51 \pm 0.01$ & $157.76 \pm 1.01$ & $15.34 \pm 0.12$ & $0.36 \pm 0.02$ & 181.7 \\
\hline MI 3 & $1.07 \pm 0.01$ & $8.38 \pm 0.19$ & $1.48 \pm 0.05$ & $2.21 \pm 0.14$ & $206.59 \pm 0.46$ & $20.91 \pm 0.12$ & $0.43 \pm 0.03$ & 241.1 \\
\hline MI 4 & $1.05 \pm 0.05$ & $6.23 \pm 0.07$ & $1.23 \pm 0.03$ & $1.68 \pm 0.04$ & $162.27 \pm 0.59$ & $14.68 \pm 0.12$ & $0.00 \pm 0.00$ & 187.1 \\
\hline MI 5 & $0.38 \pm 0.02$ & $6.26 \pm 0.02$ & $1.45 \pm 0.02$ & $1.91 \pm 0.02$ & $174.49 \pm 0.74$ & $15.35 \pm 0.02$ & $0.00 \pm 0.00$ & 199.8 \\
\hline \multicolumn{9}{|c|}{ Cv. Madural } \\
\hline MI 3 & $0.42 \pm 0.02$ & $4.56 \pm 0.11$ & $1.84 \pm 0.08$ & $1.72 \pm 0.07$ & $157.38 \pm 0.35$ & $15.22 \pm 0.21$ & $0.37 \pm 0.04$ & 181.5 \\
\hline MI 4 & $0.48 \pm 0.06$ & $7.30 \pm 0.06$ & $3.70 \pm 0.01$ & $2.83 \pm 0.03$ & $255.35 \pm 1.07$ & $23.32 \pm 0.19$ & $0.66 \pm 0.04$ & 293.6 \\
\hline MI 5 & $0.95 \pm 0.05$ & $4.87 \pm 0.08$ & $2.71 \pm 0.05$ & $1.70 \pm 0.03$ & $152.35 \pm 0.69$ & $20.39 \pm 0.06$ & $0.55 \pm 0.06$ & 183.5 \\
\hline MI 6 & $0.36 \pm 0.03$ & $4.49 \pm 0.03$ & $2.66 \pm 0.03$ & $1.70 \pm 0.03$ & $147.38 \pm 1.25$ & $20.91 \pm 0.03$ & $0.48 \pm 0.01$ & 178.0 \\
\hline MI 4 & $0.49 \pm 0.03$ & $4.65 \pm 0.02$ & $1.35 \pm 0.00$ & $1.36 \pm 0.06$ & $142.95 \pm 0.18$ & $11.07 \pm 0.04$ & $0.34 \pm 0.01$ & 162.2 \\
\hline MI 5 & $0.37 \pm 0.03$ & $4.88 \pm 0.02$ & $2.00 \pm 0.04$ & $1.41 \pm 0.02$ & $149.00 \pm 0.42$ & $11.21 \pm 0.07$ & $0.24 \pm 0.01$ & 169.1 \\
\hline MI 6 & $0.35 \pm 0.02$ & $4.07 \pm 0.09$ & $1.62 \pm 0.18$ & $1.24 \pm 0.06$ & $120.41 \pm 0.92$ & $8.76 \pm 0.06$ & $0.00 \pm 0.00$ & 136.5 \\
\hline
\end{tabular}

${ }^{\mathrm{a}}$ Mean and standard deviation for a confidence coefficient of $95 \%$.

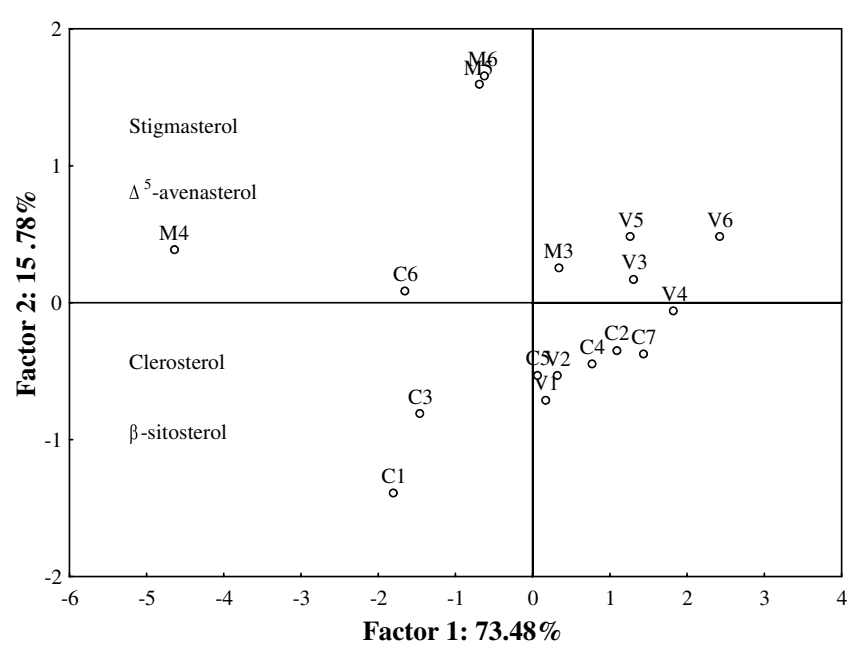

Fig. 2. Principal components analysis based on sterols profiles of Cvs. Cobrançosa, Madural and Verdeal Transmontana virgin olive oils extracted from olives with different maturation indices.

The fatty acid composition of these cultivars was studied previously (Pereira, Oliveira, Casal, \& Alves, 2002) and the results subjected to statistical analysis in order to differentiate the cultivars. The samples analyzed at that time correspond to another year crop and were collected at the same ripening stage. In this work, the oils under study were also subjected to a fatty acid analysis in order to evaluate the effect of the ripening stage on the fatty acid composition.

Tables 3-5 report the results obtained for each fatty acid identified, total saturated fatty acids (SFA), polyunsaturated fatty acids (PUFA), monounsaturated fatty acids (MUFA), total trans isomers of unsaturated fatty acids and the ratios oleic/linoleic acids and MUFA/PUFA for the three cultivars under evaluation. The now obtained values are, in general terms, in agreement with those already reported by Pereira et al. (2002) for the same cultivars in another crop year. Cv. Cobrançosa showed the highest mean value for SFA (14.65\%) while Cv. Madural showed the highest mean value for PUFA (13.06\%) and Cv. Verdeal Transmontana the highest mean value for MUFA $(82.00 \%)$. The ratios oleic to linoleic acid were also different among the cultivars and varied along the ripening; however, MANOVA results showed that differences on individual fatty acid compositions were not significant $(p>0.05)$ when maturation index was considered the independent variable. $\mathrm{Cv}$. Madural presented always the lowest value (mean value of 6.0) and $\mathrm{Cv}$. Verdeal Transmontana the highest (mean value of 28.2). In Cv. Cobrançosa the values were intermediate (mean value of 12.2). The oleic to linoleic acids ratio is frequently used as a stability parameter (Velasco \& Dobarganes, 2002) and, in previous studies, the cultivars with higher ratios were those with higher oxidative stability (data not shown).

Fatty acids results were submitted to one-way MANOVA with the purpose of testing for significant differences due to cultivar. Differences on $\mathrm{C}_{16}$ contents were not considered significant when the three cultivars were compared $(p>0.05)$. Differences on the others fatty acids were highly significant $(p<0.01)$. Wilk's lambda is the most commonly used multivariate measure and in this case was near zero (5.20E-5) indicating a perfect relationship of cultivars and responses in fatty acid composition. With the purpose of reducing variables but maximizing the variability between cultivars three fatty acids were selected to PCA 
Table 3

Fatty acid composition (percent) $)^{\mathrm{a}}$ of $\mathrm{Cv}$. Cobrançosa virgin olive oils extracted from olives with different maturation indices

\begin{tabular}{|c|c|c|c|c|c|c|c|}
\hline & MI 1 & MI 2 & MI 3 & MI 4 & MI 5 & MI 6 & MI 7 \\
\hline $\mathrm{C}_{14}$ & $0.01 \pm 0.00$ & n.d. ${ }^{a}$ & n.d. & $0.01 \pm 0.00$ & n.d. & $0.01 \pm 0.00$ & $0.01 \pm 0.00$ \\
\hline $\mathrm{C}_{16}$ & $10.43 \pm 0.27$ & $9.92 \pm 0.05$ & $9.93 \pm 0.03$ & $10.12 \pm 0.07$ & $9.01 \pm 0.10$ & $9.78 \pm 0.02$ & $9.17 \pm 0.02$ \\
\hline $\mathrm{C}_{16: 1} t$ & $0.05 \pm 0.00$ & $0.05 \pm 0.00$ & $0.05 \pm 0.00$ & $0.05 \pm 0.00$ & $0.07 \pm 0.00$ & $0.09 \pm 0.00$ & $0.10 \pm 0.00$ \\
\hline $\mathrm{C}_{16: 1} c$ & $0.34 \pm 0.01$ & $0.32 \pm 0.00$ & $0.30 \pm 0.00$ & $0.34 \pm 0.00$ & $0.26 \pm 0.00$ & $0.44 \pm 0.00$ & $0.39 \pm 0.00$ \\
\hline $\mathrm{C}_{17}$ & $0.18 \pm 0.01$ & $0.14 \pm 0.00$ & $0.14 \pm 0.00$ & $0.14 \pm 0.00$ & $0.15 \pm 0.00$ & $0.20 \pm 0.00$ & $0.19 \pm 0.00$ \\
\hline $\mathrm{C}_{17: 1} c$ & $0.26 \pm 0.01$ & $0.20 \pm 0.00$ & $0.20 \pm 0.00$ & $0.20 \pm 0.00$ & $0.20 \pm 0.00$ & $0.28 \pm 0.00$ & $0.27 \pm 0.00$ \\
\hline $\mathrm{C}_{18}$ & $3.91 \pm 0.21$ & $3.21 \pm 0.02$ & $3.95 \pm 0.04$ & $4.13 \pm 0.10$ & $4.31 \pm 0.05$ & $4.78 \pm 0.01$ & $4.84 \pm 0.00$ \\
\hline $\mathrm{C}_{18: 1} t$ & $0.01 \pm 0.00$ & n.d. & n.d. & n.d. & n.d. & $0.01 \pm 0.00$ & $0.01 \pm 0.00$ \\
\hline $\mathrm{C}_{18: 1} c$ & $76.46 \pm 1.31$ & $78.81 \pm 0.08$ & $78.00 \pm 0.15$ & $76.16 \pm 0.64$ & $77.79 \pm 0.50$ & $73.72 \pm 0.01$ & $75.35 \pm 0.02$ \\
\hline $\mathrm{C}_{18: 2} c t$ & n.d. & n.d. & n.d. & n.d. & n.d. & $0.01 \pm 0.00$ & n.d. \\
\hline $\mathrm{C}_{18: 2} c c$ & $5.28 \pm 0.01$ & $5.62 \pm 0.07$ & $5.60 \pm 0.10$ & $6.99 \pm 0.35$ & $6.35 \pm 0.28$ & $8.14 \pm 0.01$ & $7.02 \pm 0.01$ \\
\hline $\mathrm{C}_{18: 3} c c c$ & $0.63 \pm 0.01$ & $0.68 \pm 0.00$ & $0.55 \pm 0.00$ & $0.59 \pm 0.02$ & $0.61 \pm 0.01$ & $0.74 \pm 0.00$ & $0.73 \pm 0.00$ \\
\hline $\mathrm{C}_{19}$ & $0.01 \pm 0.00$ & n.d. & n.d. & n.d. & n.d. & $0.01 \pm 0.00$ & $0.01 \pm 0.00$ \\
\hline $\mathrm{C}_{20}$ & $0.44 \pm 0.02$ & $0.39 \pm 0.01$ & $0.41 \pm 0.00$ & $0.39 \pm 0.00$ & $0.40 \pm 0.00$ & $0.44 \pm 0.00$ & $0.47 \pm 0.00$ \\
\hline $\mathrm{C}_{20: 1}$ & $0.13 \pm 0.01$ & $0.16 \pm 0.00$ & $0.16 \pm 0.00$ & $0.15 \pm 0.01$ & $0.15 \pm 0.00$ & $0.22 \pm 0.00$ & $0.23 \pm 0.00$ \\
\hline $\mathrm{C}_{21}$ & $0.02 \pm 0.00$ & n.d. & n.d. & $0.02 \pm 0.00$ & n.d. & $0.02 \pm 0.00$ & $0.02 \pm 0.01$ \\
\hline $\mathrm{C}_{22}$ & $0.08 \pm 0.00$ & $0.07 \pm 0.01$ & $0.08 \pm 0.00$ & $0.08 \pm 0.01$ & $0.08 \pm 0.00$ & $0.10 \pm 0.00$ & $0.11 \pm 0.00$ \\
\hline $\mathrm{C}_{24}$ & $0.03 \pm 0.00$ & $0.02 \pm 0.00$ & $0.03 \pm 0.00$ & $0.03 \pm 0.01$ & $0.03 \pm 0.00$ & $0.05 \pm 0.00$ & $0.05 \pm 0.00$ \\
\hline$\sum \mathrm{SFAs}$ & 15.11 & 13.75 & 14.54 & 14.92 & 13.98 & 15.39 & 14.87 \\
\hline$\sum$ PUFAs & 5.91 & 6.30 & 6.15 & 7.58 & 6.96 & 8.89 & 7.75 \\
\hline$\sum$ MUFAs & 77.25 & 79.54 & 78.71 & 76.90 & 78.47 & 74.76 & 76.35 \\
\hline$\sum$ transFA & 0.06 & 0.05 & 0.05 & 0.05 & 0.07 & 0.11 & 0.11 \\
\hline $\mathrm{C}_{18: 1} / \mathrm{C}_{18: 2}$ & 14.48 & 14.02 & 13.93 & 10.90 & 12.25 & 9.06 & 10.73 \\
\hline MUFA/PUFAs & 13.07 & 12.63 & 12.80 & 10.15 & 11.27 & 8.41 & 9.85 \\
\hline
\end{tabular}

n.d. - not detected, $\sum-$ sum.

${ }^{\text {a }}$ Mean and standard deviation for a confidence coefficient of $95 \%$.

Table 4

Fatty acid composition (percent) ${ }^{\mathrm{a}}$ of $\mathrm{Cv}$. Madural virgin olive oils extracted from olives with different maturation indices

\begin{tabular}{|c|c|c|c|c|c|}
\hline & MI 3 & MI 4 & MI 5 & MI 6 & MI 7 \\
\hline $\mathrm{C}_{14}$ & $0.01 \pm 0.00$ & $0.01 \pm 0.00$ & $0.01 \pm 0.00$ & $0.01 \pm 0.00$ & $0.01 \pm 0.00$ \\
\hline $\mathrm{C}_{16}$ & $10.92 \pm 0.02$ & $10.26 \pm 0.03$ & $10.39 \pm 0.02$ & $9.98 \pm 0.05$ & $9.83 \pm 0.02$ \\
\hline $\mathrm{C}_{16: 1} t$ & $0.07 \pm 0.00$ & $0.09 \pm 0.00$ & $0.09 \pm 0.00$ & $0.09 \pm 0.00$ & $0.09 \pm 0.00$ \\
\hline $\mathrm{C}_{16: 1} c$ & $0.35 \pm 0.00$ & $0.31 \pm 0.00$ & $0.33 \pm 0.00$ & $0.32 \pm 0.01$ & $0.31 \pm 0.00$ \\
\hline $\mathrm{C}_{17}$ & $0.06 \pm 0.00$ & $0.07 \pm 0.00$ & $0.06 \pm 0.00$ & $0.06 \pm 0.00$ & $0.06 \pm 0.00$ \\
\hline $\mathrm{C}_{17: 1} c$ & $0.07 \pm 0.00$ & $0.08 \pm 0.00$ & $0.07 \pm 0.00$ & $0.08 \pm 0.00$ & $0.07 \pm 0.00$ \\
\hline $\mathrm{C}_{18}$ & $2.33 \pm 0.02$ & $2.22 \pm 0.01$ & $2.27 \pm 0.00$ & $2.19 \pm 0.00$ & $2.22 \pm 0.00$ \\
\hline $\mathrm{C}_{18: 1} t$ & $0.02 \pm 0.01$ & $0.01 \pm 0.00$ & n.d. & $0.01 \pm 0.00$ & $0.02 \pm 0.00$ \\
\hline $\mathrm{C}_{18: 1} c$ & $71.77 \pm 0.02$ & $72.56 \pm 0.05$ & $71.23 \pm 0.04$ & $71.95 \pm 0.03$ & $71.55 \pm 0.02$ \\
\hline $\mathrm{C}_{18: 2} c t$ & $0.01 \pm 0.00$ & $0.01 \pm 0.00$ & $0.01 \pm 0.00$ & $0.01 \pm 0.00$ & $0.01 \pm 0.00$ \\
\hline $\mathrm{C}_{18: 2} c c$ & $11.29 \pm 0.02$ & $11.43 \pm 0.02$ & $12.67 \pm 0.00$ & $12.27 \pm 0.01$ & $12.85 \pm 0.01$ \\
\hline $\mathrm{C}_{18: 3} c c c$ & $0.89 \pm 0.00$ & $0.93 \pm 0.00$ & $0.99 \pm 0.02$ & $0.98 \pm 0.02$ & $0.94 \pm 0.01$ \\
\hline $\mathrm{C}_{19}$ & n.d. & n.d. & n.d. & $0.01 \pm 0.00$ & $0.01 \pm 0.00$ \\
\hline $\mathrm{C}_{20}$ & $0.33 \pm 0.00$ & $0.33 \pm 0.00$ & $0.32 \pm 0.00$ & $0.32 \pm 0.00$ & $0.31 \pm 0.00$ \\
\hline $\mathrm{C}_{20: 1}$ & $0.32 \pm 0.00$ & $0.33 \pm 0.01$ & $0.32 \pm 0.00$ & $0.34 \pm 0.01$ & $0.34 \pm 0.00$ \\
\hline $\mathrm{C}_{21}$ & $0.01 \pm 0.00$ & $0.02 \pm 0.00$ & $0.02 \pm 0.00$ & $0.02 \pm 0.00$ & $0.02 \pm 0.00$ \\
\hline $\mathrm{C}_{22}$ & $0.09 \pm 0.00$ & $0.10 \pm 0.00$ & $0.09 \pm 0.00$ & $0.09 \pm 0.00$ & $0.09 \pm 0.00$ \\
\hline $\mathrm{C}_{24}$ & $0.04 \pm 0.00$ & $0.04 \pm 0.00$ & $0.04 \pm 0.00$ & $0.03 \pm 0.00$ & $0.03 \pm 0.00$ \\
\hline$\sum$ SFAs & 13.79 & 13.05 & 13.20 & 12.71 & 12.58 \\
\hline$\sum$ PUFAs & 12.19 & 12.37 & 13.67 & 13.26 & 13.80 \\
\hline$\sum$ MUFAs & 72.60 & 73.38 & 72.04 & 72.79 & 72.38 \\
\hline$\sum$ transFA & 0.10 & 0.11 & 0.10 & 0.11 & 0.12 \\
\hline $\mathrm{C}_{18: 1} / \mathrm{C}_{18: 2}$ & 6.36 & 6.35 & 5.62 & 5.86 & 5.57 \\
\hline MUFA/PUFAs & 5.96 & 5.93 & 5.27 & 5.49 & 5.24 \\
\hline
\end{tabular}

n.d. - not detected, $\sum-$ sum.

${ }^{a}$ Mean and standard deviation for a confidence coefficient of $95 \%$.

analysis. The selection of $\mathrm{C}_{18}, \mathrm{C}_{18: 1}$ and $\mathrm{C}_{18: 2}$ was justified by their significant differences $(p<0.01)$ and by their abundance in the oils. By the observation of eigenvalues we con- clude that two factors were sufficient to justify $99.58 \%$ of the total variance (Factor 1: 68.16\%; Factor 2: $31.42 \%$ ). With the factors coordinates of the variables, based on 
Table 5

Fatty acid composition (percent) ${ }^{\mathrm{a}}$ of $\mathrm{Cv}$. Verdeal Transmontana virgin olive oils extracted from olives with different maturation indices

\begin{tabular}{|c|c|c|c|c|c|c|}
\hline & MI 1 & MI 2 & MI 3 & MI 4 & MI 5 & MI 6 \\
\hline $\mathrm{C}_{14}$ & $0.01 \pm 0.00$ & $0.01 \pm 0.00$ & n.d. ${ }^{\mathrm{a}}$ & $0.01 \pm 0.00$ & n.d. & n.d. \\
\hline $\mathrm{C}_{16}$ & $10.18 \pm 0.01$ & $9.73 \pm 0.02$ & $9.54 \pm 0.01$ & $9.56 \pm 0.01$ & $9.55 \pm 0.00$ & $9.81 \pm 0.00$ \\
\hline $\mathrm{C}_{16: 1} t$ & $0.08 \pm 0.00$ & $0.08 \pm 0.00$ & $0.08 \pm 0.00$ & $0.09 \pm 0.00$ & $0.08 \pm 0.00$ & $0.07 \pm 0.00$ \\
\hline $\mathrm{C}_{16: 1} c$ & $0.43 \pm 0.00$ & $0.39 \pm 0.00$ & $0.41 \pm 0.00$ & $0.38 \pm 0.00$ & $0.43 \pm 0.00$ & $0.39 \pm 0.01$ \\
\hline $\mathrm{C}_{17}$ & $0.26 \pm 0.00$ & $0.21 \pm 0.00$ & $0.24 \pm 0.00$ & $0.21 \pm 0.00$ & $0.19 \pm 0.00$ & $0.21 \pm 0.00$ \\
\hline $\mathrm{C}_{17: 1} c$ & $0.39 \pm 0.00$ & $0.35 \pm 0.00$ & $0.37 \pm 0.00$ & $0.34 \pm 0.00$ & $0.31 \pm 0.00$ & $0.34 \pm 0.00$ \\
\hline $\mathrm{C}_{18}$ & $2.94 \pm 0.01$ & $2.74 \pm 0.01$ & $2.97 \pm 0.01$ & $2.75 \pm 0.01$ & $2.69 \pm 0.01$ & $2.78 \pm 0.00$ \\
\hline $\mathrm{C}_{18: 1} t$ & $0.01 \pm 0.00$ & $0.01 \pm 0.00$ & n.d. & $0.01 \pm 0.00$ & $0.01 \pm 0.00$ & n.d. \\
\hline $\mathrm{C}_{18: 1} c$ & $79.74 \pm 0.00$ & $80.85 \pm 0.00$ & $81.05 \pm 0.00$ & $80.90 \pm 0.00$ & $81.56 \pm 0.00$ & $81.09 \pm 0.00$ \\
\hline $\mathrm{C}_{18: 2} c t$ & n.d. & n.d. & n.d. & n.d. & n.d. & n.d. \\
\hline $\mathrm{C}_{18: 2} c c$ & $3.15 \pm 0.08$ & $2.89 \pm 0.02$ & $2.89 \pm 0.01$ & $2.89 \pm 0.04$ & $2.54 \pm 0.01$ & $2.93 \pm 0.00$ \\
\hline $\mathrm{C}_{18: 3} c c c$ & $0.72 \pm 0.03$ & $0.65 \pm 0.01$ & $0.63 \pm 0.01$ & $0.65 \pm 0.02$ & $0.58 \pm 0.01$ & $0.61 \pm 0.01$ \\
\hline $\mathrm{C}_{19}$ & $0.02 \pm 0.00$ & $0.02 \pm 0.00$ & n.d. & $0.01 \pm 0.00$ & n.d. & n.d. \\
\hline $\mathrm{C}_{20}$ & $0.49 \pm 0.01$ & $0.46 \pm 0.00$ & $0.44 \pm 0.01$ & $0.47 \pm 0.00$ & $0.44 \pm 0.02$ & $0.47 \pm 0.08$ \\
\hline $\mathrm{C}_{20: 1}$ & $0.30 \pm 0.00$ & $0.31 \pm 0.00$ & $0.27 \pm 0.02$ & $0.31 \pm 0.00$ & $0.29 \pm 0.00$ & $0.27 \pm 0.00$ \\
\hline $\mathrm{C}_{21}$ & $0.03 \pm 0.00$ & $0.02 \pm 0.00$ & n.d. & $0.02 \pm 0.00$ & $0.03 \pm 0.00$ & n.d. \\
\hline $\mathrm{C}_{22}$ & $0.15 \pm 0.00$ & $0.13 \pm 0.00$ & $0.12 \pm 0.01$ & $0.14 \pm 0.00$ & $0.13 \pm 0.01$ & $0.12 \pm 0.01$ \\
\hline $\mathrm{C}_{24}$ & $0.07 \pm 0.01$ & $0.07 \pm 0.00$ & $0.05 \pm 0.00$ & $0.07 \pm 0.00$ & $0.05 \pm 0.00$ & $0.05 \pm 0.00$ \\
\hline$\sum \mathrm{SFAs}$ & 14.15 & 13.39 & 13.36 & 13.24 & 13.08 & 13.44 \\
\hline$\sum$ PUFAs & 3.87 & 3.54 & 3.52 & 3.54 & 3.12 & 3.54 \\
\hline$\sum$ MUFAs & 80.95 & 81.99 & 82.18 & 82.03 & 82.68 & 82.16 \\
\hline$\sum$ transFA & 0.09 & 0.09 & 0.08 & 0.10 & 0.07 & 0.07 \\
\hline $\bar{C}_{18: 1} / C_{18: 2}$ & 25.31 & 27.98 & 28.04 & 27.99 & 32.11 & 27.68 \\
\hline MUFA/PUFAs & 20.92 & 23.16 & 23.35 & 23.17 & 26.50 & 23.21 \\
\hline
\end{tabular}

n.d. - not detected, $\sum-$ sum.

a Mean and standard deviation for a confidence coefficient of $95 \%$.

correlations, a projection on the factor-plane was made, leading us to understand that the cultivars near those specific locations were strongly influenced by those variables. For example, $\mathrm{Cv}$. Cobrançosa is the richer in $\mathrm{C}_{18}$ while $\mathrm{Cv}$. Madural presented the lowest $\mathrm{C}_{18: 1}$ content. Actually $\mathrm{Cv}$. Verdeal Transmontana was the richer in $\mathrm{C}_{18: 1}$ and presented the highest values of stability (measured by the Rancimat method) against the lower ones presented by Cv. Madural (data not shown). The now obtained results are in good accordance with those obtained previously, confirming the fact that the three cultivars are perfectly discrim-

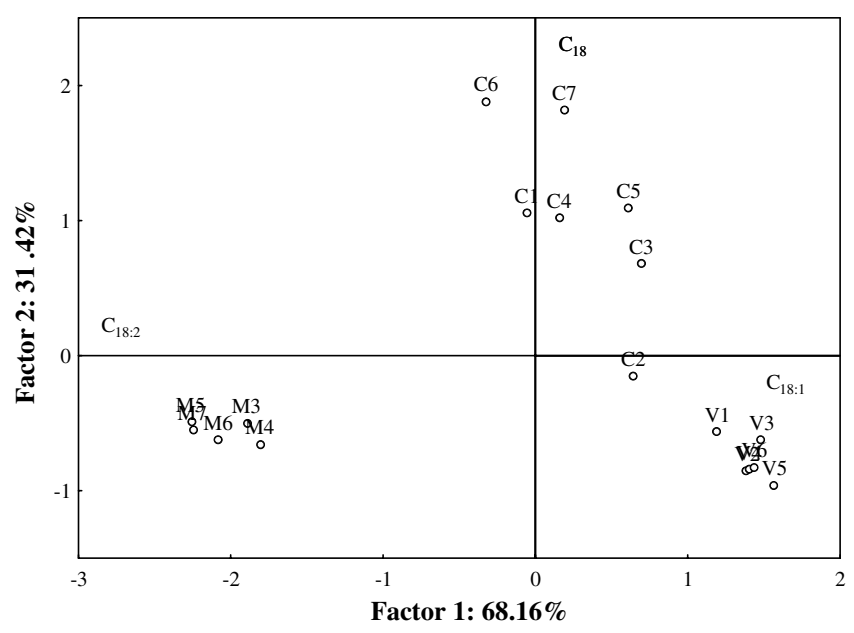

Fig. 3. Principal components analysis based on fatty acid profiles of Cvs. Cobrançosa, Madural and Verdeal Transmontana virgin olive oils extracted from olives with different maturation indices. inated by its fatty acid composition. However, the results obtained with samples in different ripening stages allow further conclusions. As can be observed (Fig. 3) the Cvs. Verdeal Transmontana and Madural, appear as a very homogeneous group where the MI has almost no influence, while cv. Cobrançosa presents an evident dispersion of values. In this last cultivar, with the exception of sample with MI 1, there is an increase of stearic acid as ripening proceeds.

Global PCA and cluster analysis were performed with all the chemical parameters considered statistical relevant in

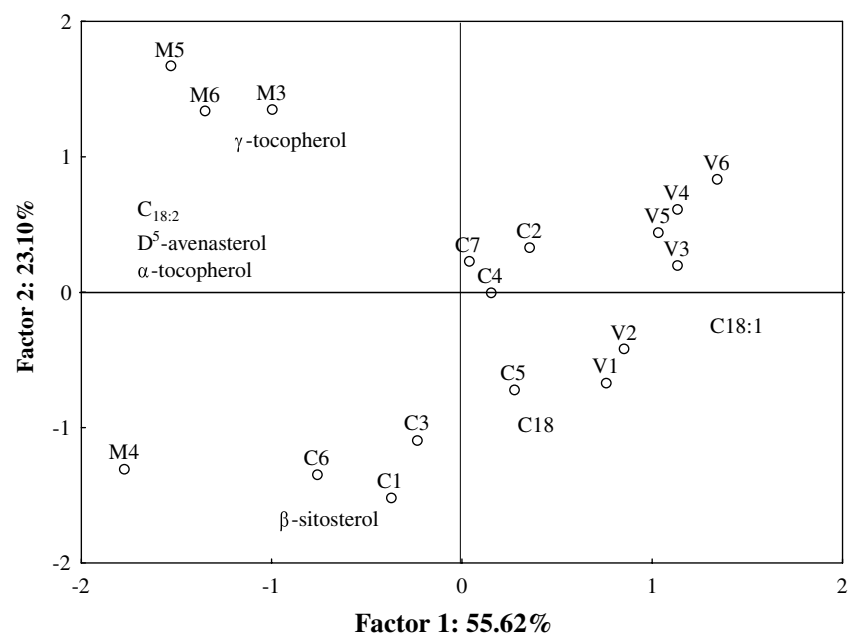

Fig. 4. Principal components analysis based on all relevant chemical parameters of Cvs. Cobrançosa, Madural and Verdeal Transmontana virgin olive oils extracted from olives with different maturation indices. 


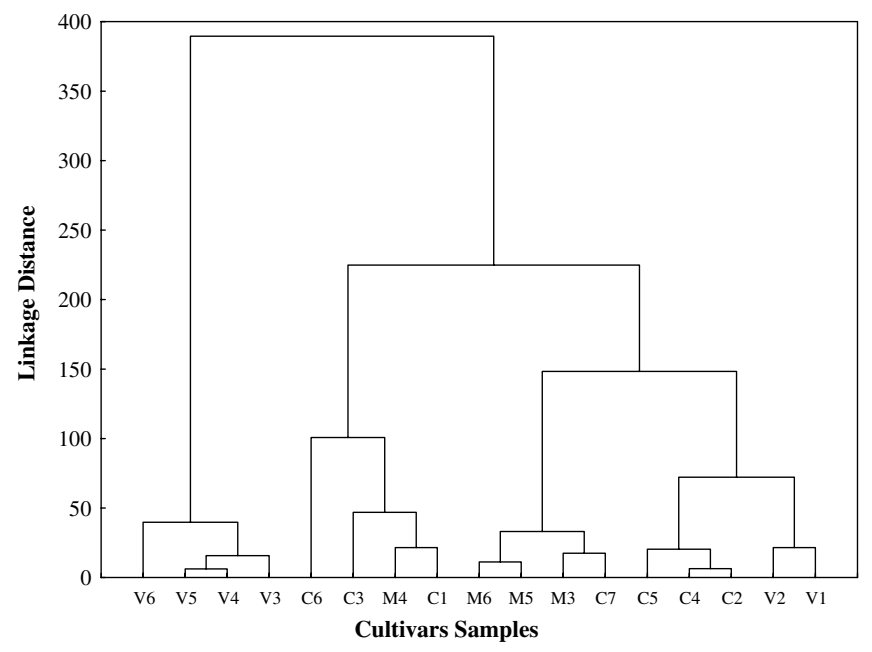

Fig. 5. Cluster analysis based on all relevant chemical parameters of Cvs. Cobrançosa, Madural and Verdeal Transmontana virgin olive oils extracted from olives with different maturation indices.

order to observe similarities between the samples and also to compare both methods. As can be seen in Fig. 4, the discrimination of cultivars was accomplished, although some elements were distant from the formed groups. In cluster analysis (Fig. 5) we also observed the formation of groups based on the similarities between the samples. In this case, the formation of clusters and its linkage could be compared and related with the groups formed in PCA. For example, the cluster composed by Cvs. V6, V5, V4, V3, could be related with the group plotted in Fig. 4, with samples Cvs. V5 and V4 being very similar in what concerns the chemical parameters evaluated and used in these analysis.

Table 6 summarizes the discriminate variable factors of principal components based in the parameters evaluated.

Table 6

Discriminate variables factors of principal components analysis based on fatty acids, sterol and tocopherols compositions

\begin{tabular}{lcr}
\hline Variable & Factor 1 & Factor 2 \\
\hline $\mathrm{C}_{16}$ & 0.538 & -0.459 \\
$\mathrm{C}_{16: 1} c$ & -0.616 & -0.578 \\
$\mathrm{C}_{17}$ & -0.961 & -0.189 \\
$\mathrm{C}_{17: 1} c$ & -0.958 & -0.259 \\
$\mathrm{C}_{18}$ & -0.447 & 0.747 \\
$\mathrm{C}_{18: 1} c$ & -0.908 & -0.131 \\
$\mathrm{C}_{18: 2} c c$ & 0.96 & 0.129 \\
$\mathrm{C}_{18: 3} c c c$ & 0.874 & -0.324 \\
$\mathrm{C}_{20}$ & -0.957 & -0.148 \\
$\mathrm{C}_{20: 1} c$ & 0.348 & -0.877 \\
$\mathrm{Cholesterol}$ & & -0.580 \\
$\mathrm{Campesterol}_{\text {Stigmasterol }}$ & 0.389 & -0.550 \\
Clerosterol & 0.773 & 0.534 \\
$\beta$-Sitosterol & 0.630 & -0.092 \\
$\Delta^{5}$-Avenasterol & 0.961 & -0.195 \\
$\Delta^{7}$-Avenastenol & 0.924 & 0.316 \\
$\alpha$-Tocopherol & 0.803 & 0.656 \\
$\beta$-Tocopherol & 0.502 & 0.673 \\
$\gamma$-Tocopherol & -0.739 & -0.209 \\
\hline
\end{tabular}

Factors entry (relevant entries |Factor $\mid>0.70$ ).
In conclusion, it can be said that the olive oils subject of this study show good nutritional characteristics in what the analyzed parameters are concerned. Besides, it was possible to conclude that the results obtained for such parameters allow the differentiation of the cultivars. The variables chosen to differentiate the cultivars also permitted, in some cases, to appreciate the influence of the maturation index. Probably each varietal olive oil characteristics contribute to the unique characteristics of Trás-Os-Montes olive oils, a PDO Portuguese product.

\section{References}

Aguilera, M. P., Beltrán, G., Ortega, D., Fernández, A., Jiménez, A., \& Uceda, M. (2005). Characterisation of virgin olive oil of Italian olive cultivars "Frantoio" and "Leccino" grown in Andalusia. Food Chemistry, 89, 387-391.

Azzi, A., \& Stocker, A. (2000). Vitamin E: non-antioxidant roles. Progress in Lipid Research, 39, 231-255.

Beltrán, G., Aguilera, M. P., Del Rio, C., Sanchez, S., \& Martinez, L. (2005). Influence of fruit ripening process on the natural antioxidant content of Hojiblanca virgin olive oils. Food Chemistry, 89, 207-215.

Firestone, D., \& Reina, R. J. (1996). Authenticity of vegetable oils. In P. R. Ashurst \& M. J. Dennis (Eds.), Food authentication (pp. 198-285). London: Chapman \& Hall.

Gama, P., Casal, S., Oliveira, B. P. P., \& Ferreira, M. (2000). Development of an HPLC/diodoarray/fluorimetric detector method for monitoring tocopherols and tocotrienols in edible oils. Journal of Liquid Chromatography and Related Technologies, 23, 3011-3022.

Garcia, J. M., Seller, S., \& Pérez-Camino, M. C. (1996). Influence of fruit ripening on olive oil quality. Journal of Agriculture and Food Chemistry, 44, 3516-3520.

Gimeno, E., Fitó, M., Lamuela-Raventós, R. M., Castellote, A. I., Covas, M., \& Farré, M. (2002). Effect of ingestion of virgin olive oil on human low-density lipoprotein composition. European Journal of Clinical Nutrition, 56, 114-120.

Gutiérrez, F., Jímenez, B., Ruíz, A., \& Albi, M. A. (1999). Effect of olive ripeness on the oxidative stability of virgin olive oil extracted from the varieties Picual and Hojiblanca and on the different components involved. Journal of Agricultural and Food Chemistry, 47, 121-127.

Gutiérrez, F., Varona, I., \& Albi, M. A. (2000). Relation of acidity and sensory quality with sterol content of olive oil from stored fruit. Journal of Agricultural and Food Chemistry, 48, 1106-1110.

Hermoso, M., Uceda, M., Garcia, A., Morales, B., Frias, M. L., \& Fernández, A. (1991). Elaboracion de aceite de calidad. Sevilla, Spain: Consejeria de Agricultura y Pesca, Serie Apuntes 5/92.

Kamm, W., Dionisi, F., Hischenhuber, C., \& Engel, K. (2001). Authenticity assessment of fats and oils. Food Reviews International, 17, 249-290.

Kiritsakis, A. K. (1998). Olive oil from the tree to the table. Trumbull, CT, USA: Food \& Nutrition Press, Inc.

Mateos, R., Dominguez, M. M., Espartero, J. L., \& Cert, A. (2003). Antioxidant effect of phenolic compounds alpha-tocopherol and other minor components in virgin olive oil. Journal of Agricultural and Food Chemistry, 51, 7170-7175.

Medeiros, M. D. (2001). Olive oil and health benefits. In R. E. C. Wildman (Ed.), The handbook of nutraceuticals and functional foods (pp. 261-267). Boca Raton, FL: CRC Press.

NP EN ISO 12228 (1999). Animal and vegetable fats and oils. Determination of individual and total sterols contents. Gas chromatographic method.

Oliveira, M. B. P. P., \& Ferreira, M. A. (1996). Capillary gas chromatographic evaluation of trans-fatty acid content of food produced under the traditional conditions of semi-industrial frying. Journal of High Resolution Chromatography, 19(3), 180-182.

Pereira, J. A., Oliveira, M. B., Casal, S., \& Alves, M. R. (2002). Discrimination of varietal olive oils of the Portuguese cultivars 
Cobrançosa, Madural and Verdeal Transmontana based on their fatty acids composition. Acta Horticultura, 586, 591-594.

Rotondi, A., Bendini, A., Cerretani, L., Mari, M., Lercker, G., \& Toschi, T. G. (2004). Effect of olive ripening degree on the oxidative stability and organoleptic properties of cv. Nostrana di Brisighella extra virgin olive oil. Journal of Agricultural Food Chemistry, 52, 3649-3654.

Salvador, M. D., Aranda, F., \& Fregapane, G. (1998). Chemical composition of commercial Cornicabra virgin olive oil from 1995/96 and 1996/97 crops. JAOCS, 75, 1305-1311.
Salvador, M. D., Aranda, F., \& Fregapane, G. (2001). Influence of fruit ripening on "Cornicabra" virgin olive oil quality. A study of four successive crop seasons. Food Chemistry, 73, 45-53.

Velasco, J., \& Dobarganes, C. (2002). Oxidative stability of virgin olive oil. European Journal of Lipid Science and Technology, 104, 661-676.

Zamora, R., Alaiz, M., \& Hidalgo, F. J. (2001). Influence of cultivar and fruit ripening on olive (Olea europaea) fruit protein content, composition, and antioxidant activity. Journal of Agricultural and Food Chemistry, 49, 4267-4270. 